\title{
Accusative Licensing of Nouns in Turkish
}

\author{
Ercan Solak*
}

\begin{abstract}
The observation that some Turkish nouns license accusative marking of their complements has puzzled linguistics for the last three decades. The first and the most common hypothesis is that such nouns are part of light-verb compounds in their infinitive nominal form where the verbal part is dropped. In this paper, I argue that light-verb hypothesis is incorrect by providing several constructions where it fails to account for. I propose an alternative, two-part hypothesis. The first part is independent of the light-verb constructions and claims that in Turkish, the accusative case is licensed by verb stems rather than finite verbs. This is a natural corollary of a yet larger hypothesis about the structure of syntax trees for languages like Turkish which claims that the syntax trees go deeper than the word level. The leaves of such trees are morphemes or morpheme groups and the whole of infection/derivation is considered within a single morphosyntactic structure. The implication is that as far as the case-licensing is concerned, only the verb stems license accusative case. In constructions where a deverbal noun seems to be licensing accusative case, it is actually the verb stem in the noun's derivation tree that licenses the accusative case. The second part of the hypothesis is the claim that the case-licensing nouns are actually lexicalizations involving multiple adjacent leaves in the morphosyntactic tree. The most common manifestations of this are the lexicalizations of verb stem-participle pairs through replacement with templatic surface forms borrowed from Arabic. The new proposal naturally explains the observation that accusative licensing is most common for a small set of words borrowed from Arabic. I illustrate that these words are the templatic forms of their multi-morpheme counterparts in Turkish which correspond to deverbal nouns, adjectives or adverbs.
\end{abstract}

Keywords. Case licensing; light-verb compounds; Turkish

1. Introduction. In Turkish, accusative case is normally licensed by verb. However, we also observe some nouns licensing accusative case of their complements in noun phrases. This observation puzzled linguistics for the last several decades, (Sezer 1991; p. 51), (Kornfilt 2003), (Keskin 2009), (Libert 2008), (Akkuş 2015), (Tat 2020). Although there have been some hypotheses to explain their structure, there has not been a consistent solution that fits well with the rest of the language structure.

First, we provide a few examples illustrating the unusual licensing of accusative case.

öğrenci-ler-i ikna zor-dur

student-PLU-ACC convincing difficult-COP.AOR

'convincing students is difficult'

In the phrase ögrrencileri ikna 'convincing students' in (1), the noun ikna 'convincing' licenses accusative marking of its complement ögrenciler 'students'.

Although not examplified in the literature before, it is also possible to observe some adjectives licensing accusative case. In fact, this is not so surprising since in Turkish, there is not much difference between the morphosyntactic behaviour of adjective and noun, (Lewis 2000; p. 50).

\footnotetext{
* Işık University, Istanbul, Turkey (ercan.solak@isikun.edu.tr)
} 
In (2), the phrase nitelikleri haiz 'possessing the qualifications' serves as the adjectival phrase before the noun adam 'man'. The adjective head haiz 'possessing' of the phrase licenses the accusative marking of nitelikler 'qualifications'.

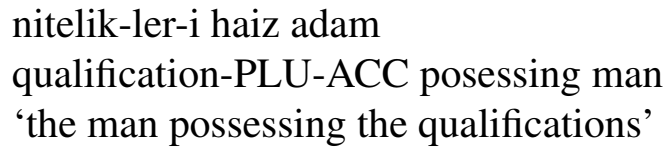

The most common explanation for accusative case licensing is the light-verb (LV) drop hypothesis (LVDH). According to LVDH, a case-licensing noun is actually part of a noun-LV compound but the LV part is dropped, (Sezer 1991). Therefore, the construction in (1) is claimed to be related to the construction in (3).

(3) öğrenci-ler-i ikna (et-mek) zor-dur

student-PL-ACC convincing (do-INF) difficult-COP.AOR

'(doing) convincing students is difficult'

Thus, by invoking a zero-surface LV in the final construction, LVDH helps to keep the licensing of accusative case in the exclusive ownership of verbs. An intuitive argument for LVDH is that, since LV compounds naturally license accusative case, their shortened versions without the LV part keeps the licensing as a kind of a placeholder.

2. Arguments against LVDH. Before I provide the details of my proposal for the explanation of accusative licensing of some nouns, I now lay out my main argument against LVDH.

The intuition behind LVDH entails a symmetric correspondence between compounds and their constituent nouns with the LV part dropped. However, there are examples where the symmetry is clearly broken. First, there are accusative case licensing nouns without a corresponding natural LV compound.

In (4), the adjective müdrik 'aware' licenses the accusative case on the possessive marked noun kabahati 'his crime'. Under LVDH, we would expect to have a lexicalized LV compound like müdrik etmek/olmak 'aware do/be'. Yet, there is no such compound. The trivial compound müdrik olmak 'be aware' is not lexicalized.

(4) Kabahat-i-ni müdrik bir adam

Crime-POSS.3.SG-ACC aware a man

'a man who is aware of his crime'

The break of symmetry is not confined to nouns or adjectives. There are also accusative case licensing adverbs without a corresponding lexicalized LV compound.

In (5), the Adverbs müteakiben/müteakip 'following' license Accusative case on their complement namaz 'prayer' yet they never occur as part of a LV compound such as müteakiben etmek/olmak 'following do/be'.

namaz-1 müteakiben/müteakip defned-il-ecek

prayer-ACC following bury-PASS-FUT-3.SG

'he will be buried following the prayer'

The symmetry can be broken in the other direction as well. There are LV compounds whose noun part does not license accusative case on its own. In (6) and (7), dropping the LV is not allowed. 
(6) a. Bun-lar-1 not et-mek zor-dur

this-PL-ACC note do-INF difficult-COP.AOR-3.SG

'it is difficult to make note of these'

b. *Bun-lar-1 not zordur this-PL-ACC note difficult-COP.AOR-3.SG

(7) a. ben-i memnun et-mek zordur me-ACC pleased do-INF difficult-COP.AOR-3.SG

'it is to difficult to please me'

b. *ben-i memnun zordur

me-ACC content difficult-COP.AOR-3.SG

In particular, nouns borrowed from the participle forms of French verbs seem not to license accusative case although their LV compounds regularly do so as illustrated in (8) and (9) with the borrowed participle nouns revize 'revised' and şoke 'shocked'.

(8) a. öykü-yü revize et-ti-m

story-ACC revised do-PAST-1.SG

'I revised the story'

b. *öykü-yü revize-m story-ACC revised-POSS.1.SG

'my revision of the story'
a. herkes-i şoke et-ti-n
everyone-ACC shocked do-PAST-2.SG
'You shocked everyone'
b. *herkes-i şoke-n
everyone-ACC shocked-POSS.2.SG
'your shocking of everyone'

The preceeding discussion shows that, as far as the licensing behaviour is concerned, the noun part of a LV compound is not tightly coupled to the whole LV compound. Therefore, the licensing can not stem from an imaginary LV compound. It must be something with the particular class of nouns itself that licenses the accusative case.

Another indication for the source of accusative licensing is supplied in the behaviour of LV compounds with the LV olmak 'be'. In (10), the LV compound haiz olmak 'to possess' licenses the accusative case on its argument bu vasıflar 'these attributes'. However, the intransitive verb olmak 'be' never licenses accusative case on its own when used outside a compound. This difference of licensing behaviour between isolated and within-compound verb seems to be in conflict with the headedness of the compound. Therefore the licensing must be enabled by the noun part of the compound, not its LV part.

bu vasif-lar-1 haiz ol-mal1-sin

this attribute-PLU-ACC possessing be-NECC-2.SG

'You must have these attributes'

The final argument against LVDH comes from the observation that noun parts of LV compounds participate in all kinds of syntactic formations. In examples (11), (12) and (13), the noun part teslim 'submission' of the LV compound teslim et-mek 'to submit' participate in different kinds of 
morphosyntactic behavior which are naturally expected of nouns. It is difficult to stipulate a LV drop for each of such cases. Instead, it is more plausible to accept the default position that these are proper nouns in the common constructions but something in their semantics enable accusative case licensing without LV drop.

Genitive-Possessive phrase:

(11) ödev-ler-in teslim-i

homework-PL-GEN submission-POSS

'submission of homeworks'

Adjective-Noun phrase:

(12) son teslim

last submission

Subject of a finite verb:

teslim ertele-n-di

submission pospone-PASS-PAST-3.SG

'the submission has been postponed'

3. Proposed structure. I claim that some nouns license accusative case indirectly through a mechanism of partial tree replacement with borrowed nouns which have deverbal semantics.

In order to elaborate the details of the claim, first I propose a new attachment schema for the arguments/complements/adjuncts of verbs.

3.1. Attachment of Verb COMPLEMENTS. Since Turkish is an agglutinative language, it is natural that its syntax trees go deeper than word level. Indeed, the leaves of syntax trees are morphemes or morpheme groups.

I propose a structure where the arguments/complements/adjuncts of a verb are merged to the verb stem before any derivation or inflection. A similar argument for late-attachment of inflection is found in (Hankamer 2004). Here, I take verb stem to be the part that includes up to and including any voice suffixes.

I use a similar early attachment for case marking of noun phrases. All the qualifiers like adjectives are attached to the nominal stem before the attachment of case suffix.

An example tree representing such an early attachment structure is given in Figure 1 for the sentence in (14).

$$
\begin{aligned}
& \text { sarı kedi-yi gör-en köpek } \\
& \text { yellow cat-ACC see-PTCP dog } \\
& \text { 'the dog who saw/sees the yellow cat' }
\end{aligned}
$$

In the syntax tree in Figure 1, the noun kedi 'cat' first merges on the left with the adjective sarl 'yellow' to form a NP. The accusative marking - $(y) I$ then merges on the left with this whole NP to form a marked phrase labeled as NP-ACC. Thus, the accusative marking is not just on the head of the NP but the whole NP. This is in parallel with the following discussion where I propose an early attachment of verb complement before any verb inflection.

In the tree in Figure 1 and in the trees in the following discussion, I adopt a flatter notation which does not explicitly indicate heads of phrases. This is to make my arguments decoupled from the question of how well X-bar theory can be fitted into Turkish morpho-syntax. Moreover, 


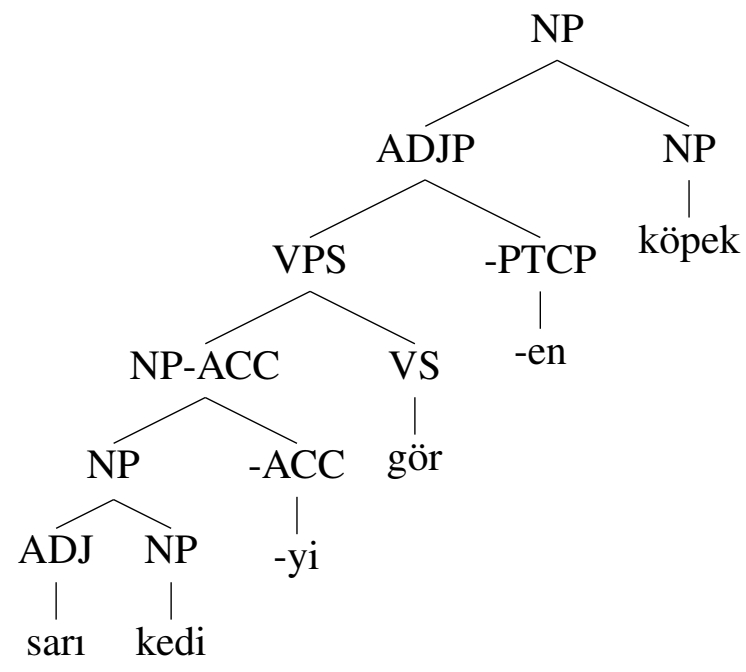

Figure 1. The syntax tree illustrating the early left-attachement of verb complements to verb stem.

in the following treatment, I do not make any assumptions regarding the internal mechanism (e.g. feature checking) that brings about the case assignment.

The accusative marked object sarı kediyi first merges with the verb stem gör 'see' to form a stemmed verb phrase labeled as VPS, which then merges with the participle -en to form an ADJP. Thus, the accusative marked phrase becomes the complement of the verb stem rather than that of the deverbal adjective gören. Note that the structure in Figure 1 has the relative clause structure as deverbal adjective phrase as proposed in (Solak 2019) rather than the one proposed in (Kornfilt 2000).

In this new structure, the accusative case marking is licensed by the verb stem, rather than a deverbal adjective as would be the case in the Figure 2.

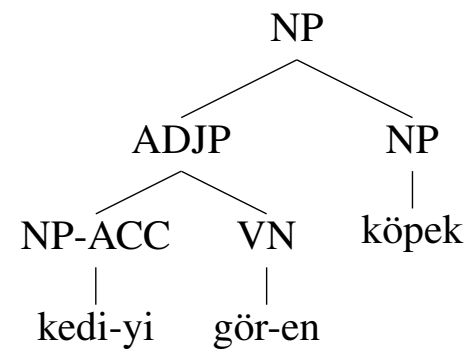

Figure 2. The incorrect syntax where the accusative marked NP is a complement of the deverbal adjective.

In order to have a structure as in Figure 2, we would need to stipulate that deverbal nouns or adjectives license accusative marking. However, that would not be enough. For completeness, we would also need to do the same for deverbal infinitives (cf. kedi-yi gör-mek 'seeing the cat') as well as for deverbal adverbs (cf. kedi-yi gör-erek 'while seeing the cat'). Instead, restricting accusative case to the object complements of verb stems and introducing stem-level left-merge is simpler and has more explanatory power. Moreover, as I argue in the rest of the paper, it helps explain the curious case of accusative licensing of nouns which are not deverbally derived. 
The question of where the case licensing occurs is also taken up in (Öztürk 2005) where the author argues against a vP layer licensing case.

3.2. BorRowing. Equipped with the new morpheme level syntactic merge approach, we now return to the main problem.

In the literature on the problem of the case-licensing of nouns, the usage examples all involve nouns of Arabic origin. Although I will give examples below which show that this does not have to be the case, for now, I will take this approximate observation about Arabic-borrowing as the starting point of my argument.

Consider the two phrases, (15) in Turkish and (16) in Arabic which are literal translations of each other. In (16), MSDR denotes the infinitive (masdar) template for this particular class of verbs in Arabic.

(15) iş-i tamamla-mak

work-ACC complete-INF

'completing the work'

(16) ikmal al-'amil-a

complete.MSDR the-work-ACC

'completing the work'

Comparing (15) and (16) as a word by word translation up to a word/morpheme order, we see that there is a correspondence between tamamlamak in (15) and ikmal in (16). Indeed, replacing the Turkish infinitive with the Arabic one yields the acceptable phrase (17) in Turkish.

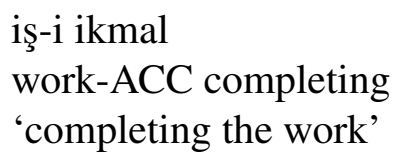

The replacement is highlighted in the syntax tree of (15) in Figure 3. In the tree on the right, the leaves $\mathrm{w}_{1}$ and $\mathrm{w}_{2}$ together correspond to the borrowed word ikmal, so $\mathrm{w}_{1} \mathrm{w}_{2}=i k m a l$. We see that the borrowed transitive masdar ikmal replaces two nodes VS and -INF at the same time in the syntax tree of (15), while keeping the rest the same.
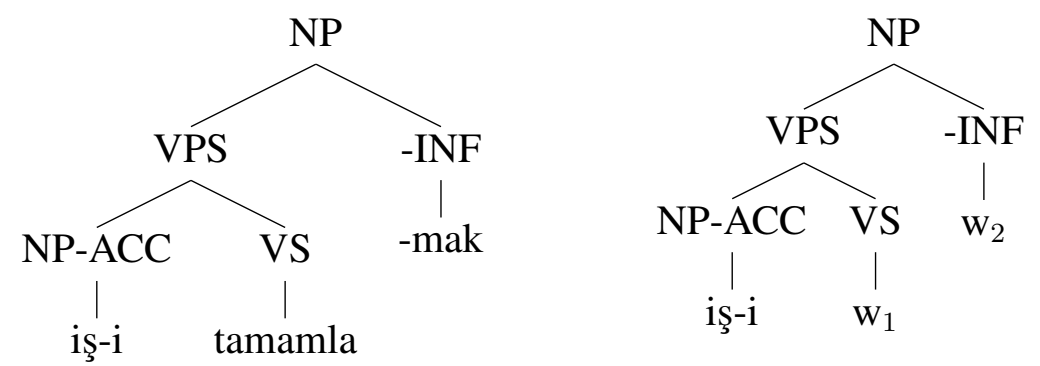

Figure 3. The syntax trees for (15) and (17). The two leaves $\mathrm{w}_{1}$ and $\mathrm{w}_{2}$ satisfy $\mathrm{w}_{1} \mathrm{w}_{2}=i k m a l$

Since Arabic has a templatic morphology, there is no obvious way to separate the original $i \mathrm{kmal}$ into two nodes and match with the two leaves of the original tree. Instead, I will use indices to indicate the span of the replacement. In the new tree, I will map the borrowed form to the verb stem leaf and map the infinitive suffix to null surface form. The new trees are shown in Figure 4. 
The matching indices also denote the restriction that these two nodes are part of the same derivation and need to be adjacent in the surface form.
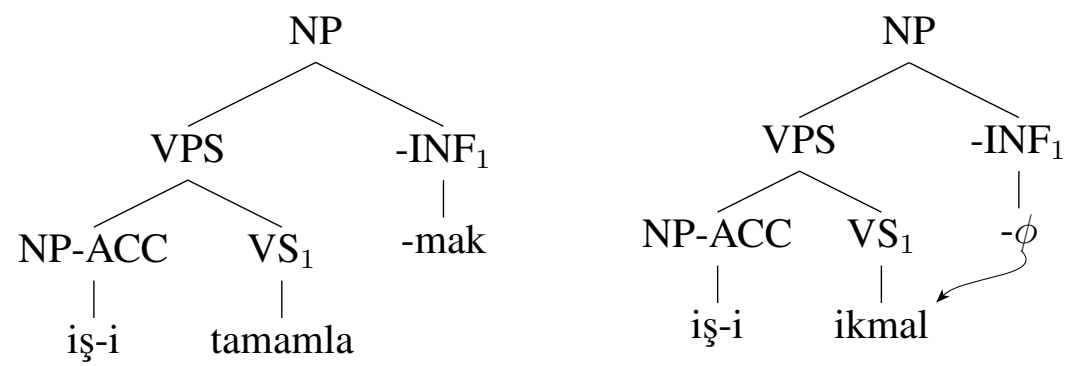

Figure 4. The indexed correspondence between the original and borrowed forms. The infinitive suffix is assumed embedded within the templatic morphology of the borrowed form and hence is shown as null in the surface.

The preceeding argument can easily be generalized to all deverbal suffixes, not just infinitives. For example, in (18), the deverbal suffix is the nominal participle -(y)An. The original and the replaced trees are shown in Figure 5. Here, the borrowed form müdrik 'understander' replaces the deverbal adjective 'anla-yan. The borrowed form müdrik itself is actually an Arabic deverbal noun templatically derived with the template 'muCCiC'.

durum-u müdrik

situtation-ACC aware

'one who understands the situation'
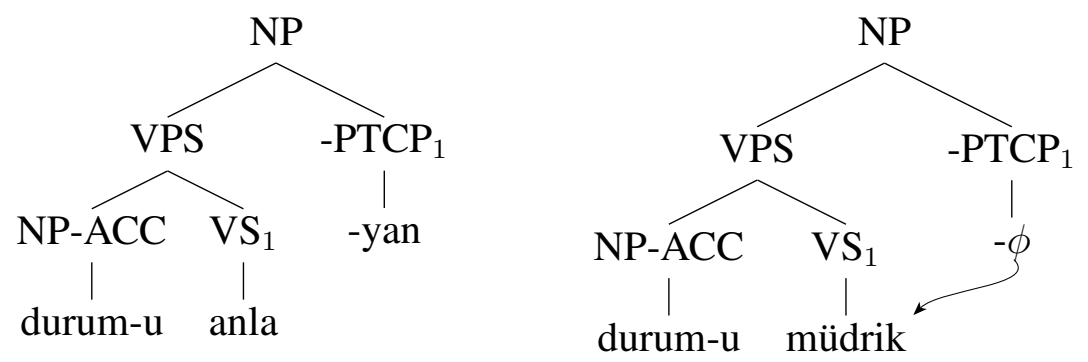

Figure 5. Indexed correspondence between the original and the borrowed forms for (18).

Note that I illustrate the replacement as a way of literal translation only as an illustration of the mechanism. In the preceeding examples, I specifically chose cases where there is an obvious 'native' lexical form for the borrowed form. In fact, for a borrowed masdar or deverbal adjective/noun, there need not be a corresponding native verb stem in Turkish. Indeed, there are quite a few borrowed words for which there are no obvious single-stem translations in the current snapshot of the lexicon, e.g. takdir 'to appreciate', fetih 'conquest', isgal 'occupation'. This might be due the fact that the original stem dropped out of usage or that the borrowed word did not correspond to an already lexicalized concept in the first place. Whatever the historical reason, borrowing seems to obey the semantic slot created by the morphosyntactic structure in the tree. The only requirement is that, the borrowed form is inserted into the general syntactic template given in Figure 6. 

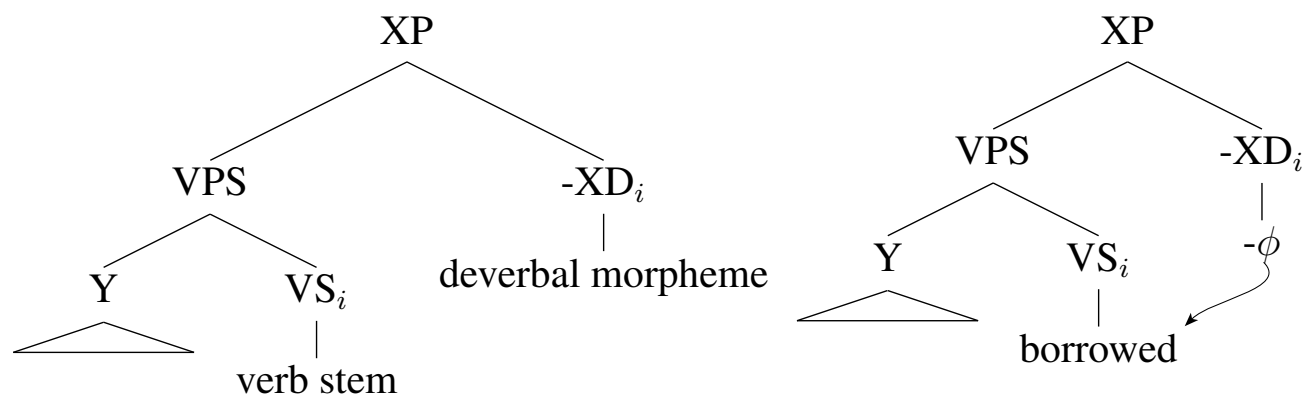

Figure 6. Morphosyntactic template for inserting borrowed forms into a verb frame.

In Figure 6, -XDi denotes a deverbal suffix that derives into category $\mathrm{X}$ (noun, adjective or adverb) out of verb stems. XP denotes the resulting phrase in that category. Y denotes any complement or adjunct of the verb stem.

Note that, the structure in Figure 6 is more general than the one for accusative case. For licensing accusative case, the complement $\mathrm{Y}$ is a phrase marked with accusative case marker $-(y) I$. For example, Figure 7 shows the syntax tree for the phrase deniz-e nazır 'overlooking the sea' in (19) where $\mathrm{Y}$ is a dative marked complement.

deniz-e nazır ev

sea-DAT overlooking house

'the house overlooking the sea'
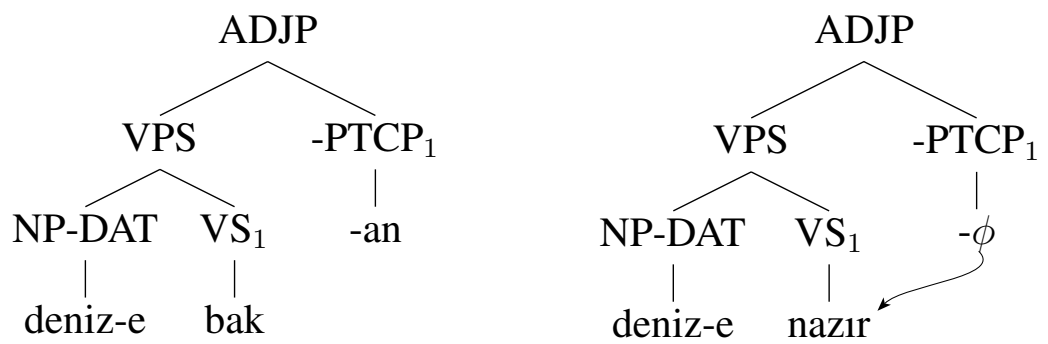

Figure 7. Derivation trees for the phrase deniz-e nazır 'overlooking the sea' in (19).

4. Generalization. In the preceeding discussion, the examples all involved borrowings from Arabic and it might seem like accusative case licensing is confined to nouns borrowed from Arabic. Actually, there are a few nouns borrowed from French that license accusative case and the proposal presented here naturally generalizes to those.

In (20), the word form sansïr 'censor' is borrowed from French without an equivalent LV compound, *sansür etmek. Instead, there is more deeply lexicalized form sansür-le-mek 'to censor'.

(20) yayın-lar-1 sansür zor

broadcast-PL-ACC censor difficult

'it is difficult to censor broadcasts'

In order to cover such cases of accusative licensing, we need to view the structure in Figure 6 at a more abstract level. Instead of positing a native current or historical verb stem that is replaced 
by a borrowed form, we can view the whole phrase as a construction with empty slots (Goldberg 1995). The construction syntax is given in Figure 8.

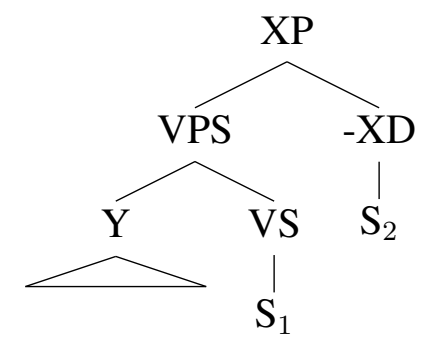

Figure 8. Construction with slots $\mathrm{S}_{1}$ and $\mathrm{S}_{2}$.

In the construction in Figure 8, the slots $S_{1}$ and $S_{2}$ need to be filled with surface forms. In the most common case, $S_{1}$ is filled with a verb stem and $S_{2}$ is filled with a deverbal suffix. However, in the rare cases, a single word form might fill both slots simultaneously. The necessary condition for this is that the semantics of the VS-XD pair must match the semantics of the single word form, borrowed or otherwise.

In (17), both slots are filled ikmal 'completing' and VS-XD semantics is that of a deverbal infinitive. In (5), those slots are filled with müteakip 'following' with VS-XD pair having adverbial semantics. Of course, all of these are conditioned by the usage and convention.

With this generalization, it is now easy to see how borrowings from French license accusative case as in (21).

a. ürün-ler-i boykot başla-dı product-PLU-ACC boycott start-PAST-3.SG 'boycotting the products started'

b. kanun-u veto cumhurbaşkanı-nın yetki-sin-de law-ACC veto president-GEN authority-POSS.3.SG-LOC 'it is within president's authority to veto the law'

5. Conclusion. In this paper, I proposed a solution to the curious case of accusative case licensing of some nouns in Turkish. First I argued against the received wisdom of light-verb drop hypothesis and showed its deficiency in fitting various cases in a consistent manner. In particular, I showed that it can not generalize to handle adverbs and adjectives that license accusative case. As part of my proposed solution, I argued that in Turkish, only verb stems license Accusative case and that the apparent conflict can be resolved considering the morphosyntactic structure of the verb stem, its complements and its deverbal suffixes. In particular, I showed that what looks like an accusative licensing for nouns is in fact a borrowed lexicalization of adjacent slots in the general construction of the syntax tree. I also showed that the solution naturally generalizes to explain the licensing of other cases as well as accusative case licensing of adjectives and adverbs.

\section{References}

Akkuş, Faruk. 2015. Light verb constructions in Turkish: A case for DP predication and blocking. In Andrew Joseph \& Esra Predolac (eds.), Proceedings of the 9th Workshop on Altaic Formal Linguistics, 133-145.

Goldberg, Adele. 1995. A construction grammar approach to argument structure. Chicago: University of Chicago Press. 
Hankamer, Jorge. 2004. Why there are two -ki's in Turkish. In Kamile İmer \& Gürkan Doğan (eds.), Current research in Turkish linguistics, Eastern Mediterranean University.

Keskin, Cem. 2009. Subject agreement-dependency of accusative case in Turkish or jumpstarting grammatical machinery: Utrecht University Ph.D. dissertation.

Kornfilt, Jaklin. 2000. Some syntactic and morphological properties of relative clauses in Turkish. In André Meinunger Artemis Alexiadou, Paul Law \& Chris Wilder (eds.), The syntax of relative clauses, John Benjamins.

Kornfilt, Jaklin. 2003. Scrambling, subscrambling, and case in Turkish. In Samin Karimi (ed.), Word order and scrambling, Blackwell Publishing.

Lewis, Geoffrey. 2000. Turkish grammar. New York: Oxford University Press 2nd edn.

Libert, Alan. 2008. Case marking of Turkic adpositional objects. In Dennis Kurzon \& Silvia Adler (eds.), Adpositions: Pragmatic, semantic and syntactic perspectives, John Benjamins.

Sezer, Engin. 1991. Issues in Turkish syntax: Harvard University Ph.D. dissertation.

Solak, Ercan. 2019. On relative clause in Turkish. In Proceedings of the 7th International Conference on Computer Processing of Turkic Languages (turklang 2019), Simferopol, Russia.

Tat, Deniz. 2020. Light verb constructions in heritage Turkish and the nature of borrowing through bilingual mixing. In 1st Heritage Language Syntax Virtual Conference, Utrecht University, The Netherlands.

Öztürk, Balk1z. 2005. Case, referentiality, and phrase structure. J. Benjamins Pub. Co. 